\title{
Transbasal versus endoscopic endonasal versus combined approaches for olfactory groove meningiomas: importance of approach selection
}

\author{
James K. Liu, MD, ${ }^{1-3}$ Nicole A. Silva, BS, ${ }^{1}$ llesha A. Sevak, BA, ${ }^{1}$ and Jean Anderson Eloy, MD ${ }^{1-4}$ \\ Departments of ${ }^{1}$ Neurological Surgery, ${ }^{2}$ Otolaryngology-Head and Neck Surgery, and ${ }^{4}$ Ophthalmology and Visual Sciences, \\ Rutgers New Jersey Medical School; and ${ }^{3}$ Center for Skull Base and Pituitary Surgery, Neurological Institute of New Jersey, \\ Rutgers New Jersey Medical School, Newark, New Jersey
}

OBJECTIVE There has been much debate regarding the optimal surgical approach for resecting olfactory groove meningiomas (OGMs). In this paper, the authors analyzed the factors involved in approach selection and reviewed the surgical outcomes in a series of OGMs.

METHODS A retrospective review of 28 consecutive OGMs from a prospective database was conducted. Each tumor was treated via one of 3 approaches: transbasal approach $(n=15)$, pure endoscopic endonasal approach $(E E A ; n=5)$, and combined (endoscope-assisted) transbasal-EEA $(n=8)$.

RESULTS The mean tumor volume was greatest in the transbasal $\left(92.02 \mathrm{~cm}^{3}\right)$ and combined $\left(101.15 \mathrm{~cm}^{3}\right)$ groups. Both groups had significant lateral dural extension over the orbits (transbasal 73.3\%, $p<0.001 ;$ combined 100\%), while the transbasal group had the most cerebral edema $(73.3 \%, p<0.001)$ and vascular involvement $(66.7 \%, p<0.001)$, and the least presence of a cortical cuff $(33.3 \%, p=0.019)$. All tumors in the combined group were recurrent tumors that invaded into the sinonasal cavity. The purely EEA group had the smallest mean tumor volume $\left(33.33 \mathrm{~cm}^{3}\right)$, all with a cortical cuff and no lateral dural extension. Gross-total resection was achieved in $80 \%$ of transbasal, $100 \%$ of EEA, and $62.5 \%$ of combined cases. Near-total resection (> $95 \%$ ) was achieved in $20 \%$ of transbasal and $37.5 \%$ of combined cases, all due to tumor adherence to the critical neurovascular structures. The rate of CSF leakage was $0 \%$ in the transbasal and combined groups, and there was 1 leak in the EEA group (20\%), resulting in an overall CSF leakage rate of $3.6 \%$. Olfaction was preserved in $66.7 \%$ in the transbasal group. There was no significant difference in length of stay or 30-day readmission rate between the 3 groups. The mean modified Rankin Scale score was 0.79 after the transbasal approach, 2.0 after EEA, and 2.4 after the combined approach $(p=0.0604)$. The mean follow-up was 14.5 months (range 1-76 months). CONCLUSIONS The transbasal approach provided the best clinical outcomes with the lowest rate of complications for large tumors $(>40 \mathrm{~mm})$ and for smaller tumors $(<40 \mathrm{~mm})$ with intact olfaction. The role of EEA appears to be limited to smaller, appropriately selected tumors in which olfaction is already absent. EEA also plays an important adjunctive role when combined with the transbasal approach for recurrent OGMs invading the sinonasal cavity. Careful patient selection using an individualized, tailored strategy is important to optimize surgical outcomes.

https://thejns.org/doi/abs/10.3171/2018.1.FOCUS17722

KEYWORDS olfactory groove meningiomas; endoscopic endonasal approach; transbasal approach; combined approach; skull base meningiomas; endoscopic skull base surgery; anterior skull base

$\mathrm{O}$ LFACTORY groove meningiomas (OGMs), arising from the lamina cribrosa and the frontoethmoidal suture, account for $8 \%-13 \%$ of all intracranial meningiomas. ${ }^{3,16,21,33}$ These neoplasms are intimate to the olfactory nerves and tend to infiltrate the cribriform plate, surrounding bone, and vasculature., ${ }^{1,15,16,21,23}$ The ideal sur- gical treatment is gross-total resection (GTR) with removal of invaded dura and bone (Simpson grade I), but even after surgery, recurrence rates can be as high as $30 \%$.,21 $^{1,21}$ Traditional open transcranial approaches, including the transbasal, pterional, supraorbital, and orbitopterional approaches, have been the workhorse for resecting OGMs

ABBREVIATIONS EEA = endoscopic endonasal approach; GTR = gross-total resection; LOS = length of stay; mRS = modified Rankin Scale; NTR = near-total resection; $O G M=$ olfactory groove meningioma.

SUBMITTED December 4, 2017. ACCEPTED January 3, 2018.

INCLUDE WHEN CITING DOI: 10.3171/2018.1.FOCUS17722. 
with excellent results and higher rates of GTR, especially for large tumors with lateral extension over the orbits. ${ }^{1-4}$, $6-8,14,15,18,33,34,39,40$ However, there has been increased interest in the use of the endoscopic endonasal approach (EEA) to remove tumors of the anterior skull base. , $^{611,13,22,35,40}$ Nevertheless, the role of the EEA in the treatment of OGMs as an alternative to traditional open transcranial approaches remains controversial due to higher rates of CSF leakage, lower rates of GTR, and complete loss of olfaction. ${ }^{6,21,22,40}$

In this paper, we review a single neurosurgeon's series of 28 consecutive patients who underwent surgery for resection of OGMs via one of 3 approaches: transbasal approach, EEA, or combined (endoscope-assisted) transbasal-EEA. We analyze the factors involved in approach selection and report our surgical outcomes and complications.

\section{Methods \\ Study Population}

Institutional review board approval was obtained from Rutgers New Jersey Medical School. Patients with OGM who underwent surgical treatment by a single neurosurgeon (J.K.L.) between July 2007 and November 2016 were reviewed retrospectively from a prospective database. The goal of this study was to analyze and compare the surgical outcomes of patients who underwent a transbasal approach, EEA, or combined transbasal-EEA for removal of OGM, and also analyze the factors involved in approach selection.

Patient records and diagnostic neuroimaging were reviewed. Tumor features were evaluated and included size, location, cerebral edema, vascular involvement, optic nerve involvement, and sinonasal invasion. The largest dimensions of the tumors were measured in the anteroposterior, transverse, and craniocaudal dimensions. Vascular or optic nerve involvement was defined as intimate contact with a major vessel or one or both optic nerves, respectively, as well as intraoperative observation of tumor adherence to these neurovascular structures. The presence of a cortical cuff was defined as a distinct, protective boundary of brain tissue between the tumor capsule and surrounding vasculature (anterior cerebral arteries and/or anterior communicating artery complex). ${ }^{20}$ Lateral dural extension was defined as tumor extension over the orbit or optic canal.

We also analyzed the operative approach, extent of resection, clinical outcome, postoperative complications, length of stay (LOS), and 30-day readmission. GTR (Simpson grade I or II) ${ }^{38}$ was the surgical goal in all cases. If there was tumor adherence to the optic nerve or major vasculature, an attempt was made for near-total resection (NTR), defined as $>95 \%$ tumor resection (Simpson grade IV). Hospital LOS was defined from the date of surgery to date of discharge to avoid any confounding data of early admission before the date of surgery (i.e., emergency department admission prior to surgery). Olfaction preservation was calculated only in the transbasal group where preoperative olfaction was intact. Patients chosen for EEA and the combined approach all had impaired olfaction preoperatively, and therefore, it was expected that all would be anosmic postoperatively due to the nature of the approach of resecting the cribriform plate. Postoperative neurological evaluation was defined using an adapted version of the modified Rankin Scale (mRS) score determined by neurological examination at the most recent follow-up visit (Table 1). ${ }^{5,17}$ An mRS score of 0-2 was a favorable outcome, 3-5 was a moderate outcome, and 6 was death.

Statistical analysis was completed using the 2-tailed Student t-test, chi-square test, and ANOVA where appropriate; $p<0.05$ was considered significant. Microsoft Office Excel 2011 (Microsoft Corp.) and IBM SPSS (version 23, IBM Corp.) were used.

\section{Surgical Approaches}

The operative techniques and nuances for the transbasal

TABLE 1. Cohort and tumor characteristics of 28 patients with OGMs

\begin{tabular}{|c|c|c|c|c|c|c|}
\hline Variable & Transbasal $(n=15)$ & p Value & $\operatorname{EEA}(n=5)$ & $p$ Value & Combined $(n=8)$ & $\mathrm{p}$ Value \\
\hline Mean age in yrs & $52.13(34-66)$ & & $51.07(28-58)$ & & $52.88(15-83)$ & \\
\hline \multicolumn{7}{|l|}{ Sex } \\
\hline Male & 5 & & 1 & & 3 & \\
\hline Female & 10 & & 4 & & 5 & \\
\hline Mean tumor vol in $\mathrm{cm}^{3}$ & $92.02(4.35-300.06)$ & & $33.33(15.69-60.77)$ & & $101.15(30.59-260.60)$ & \\
\hline Mean tumor diameter in $\mathrm{mm}$ & $44.5(16.9-91.4)$ & & $34.3(25.2-44.2)$ & & $50.7(41.3-74.0)$ & \\
\hline Cerebral edema & $11(73.3)$ & $<0.001^{*}$ & $3(60.0)$ & 0.70 & $2(25.0)$ & 0.17 \\
\hline Cortical cuff & $5(33.3)$ & $0.019^{*}$ & $5(100)$ & & $7(87.5)$ & $<0.001^{*}$ \\
\hline Vascular involvement & $10(66.7)$ & $<0.001^{*}$ & $0(0)$ & & $3(37.5)$ & 0.08 \\
\hline ON involvement & $7(46.7)$ & $0.004^{*}$ & $0(0)$ & & $5(62.5)$ & $0.011^{*}$ \\
\hline Lateral dural extension & $11(73.3)$ & $<0.001^{*}$ & $0(0)$ & & $8(100)$ & \\
\hline Hyperostosis & $11(73.3)$ & $<0.001^{*}$ & 2 & 0.178 & $8(100)$ & \\
\hline
\end{tabular}


approach, EEA, and combined approach are described in detail in previous publications by the senior author., ${ }^{9,25-32} \mathrm{In}$ general, the transbasal approach was used for large and giant OGMs ( $>40 \mathrm{~mm})$ extending laterally across the orbital roofs as well as for small- to medium-sized tumors where preoperative olfaction was intact for attempted olfactionsparing resection (Figs. 1 and 2). EEA was used for carefully selected, smaller tumors (approximately $<40 \mathrm{~mm}$ ) that did not have wide lateral extension over the orbits and had a cortical cuff without vascular involvement (Figs. 3 and 4). The combined transbasal-EEA was used primarily in cases of recurrent OGMs with lateral dural extension and invasion into the sinonasal cavity (Figs. 5 and 6). ${ }^{32}$ The tumor removal was performed primarily through the transbasal approach, while the EEA served as an adjunct to inspect endonasally for any remaining tumor and to perform reconstruction with a vascularized pedicled nasoseptal flap since the pericranial flap had already been utilized in a prior craniotomy.

\section{Results}

\section{Patient Characteristics}

Twenty-eight consecutive patients were treated for OGM between July 2007 and November 2016. Patients ranged in age from 15 to 83 years, with a mean age of 50.96 \pm 13.62 years; there was a clear female predominance in the patient pool (19 females and 9 males; Table 1). The most common clinical presentation included vision loss
(25\%), headaches (21.4\%), seizure or seizure-like activity (14.3\%), personality changes (14.3\%), and altered mental status $(10.7 \%)$. Seventeen patients $(60.7 \%)$ had a primary OGM, and 11 patients (39.3\%) had recurrent OGMs. In the transbasal group, $13.3 \%$ of tumors were recurrent, while the EEA group had only 1 recurrent tumor (20\%). All patients treated in the combined group had recurrent tumors that also invaded into the sinonasal cavity.

\section{Tumor Size and Characteristics}

The mean tumor volume was $92.02 \pm 97.64 \mathrm{~cm}^{3}$ in the transbasal group, $33.3 \pm 18.98 \mathrm{~cm}^{3}$ in the EEA group, and $101.148 \pm 71.24 \mathrm{~cm}^{3}$ in the combined group (Table 1). The mean tumor diameter was $44.5 \mathrm{~mm}$ (range 16.9$91.4 \mathrm{~mm}$ ) in the transbasal group, $34.3 \mathrm{~mm}$ (range 25.2$44.2 \mathrm{~mm}$ ) in the EEA group, and $50.7 \mathrm{~mm}$ (range 41.3$74.0 \mathrm{~mm}$ ) in the combined group. Tumors treated in the combined group had the largest mean tumor volume ( $\mathrm{p}$ $=0.332)$, the largest mean diameter $(\mathrm{p}=0.270)$, and the greatest amount of optic nerve involvement $(62.5 \%, \mathrm{p}=$ $0.011)$. Tumors in the transbasal group had the highest incidence of cerebral edema $(73.33 \%, \mathrm{p}<0.001)$ and vascular involvement $(66.67 \%, \mathrm{p}<0.001)$, as well as the lowest incidence of a cortical cuff $(33.3 \%, \mathrm{p}=0.019)$. Tumors in the EEA group had the smallest mean tumor diameter and tumor volume. All patients in the EEA group had a cortical cuff and no tumor adherence to the optic nerves or vasculature.
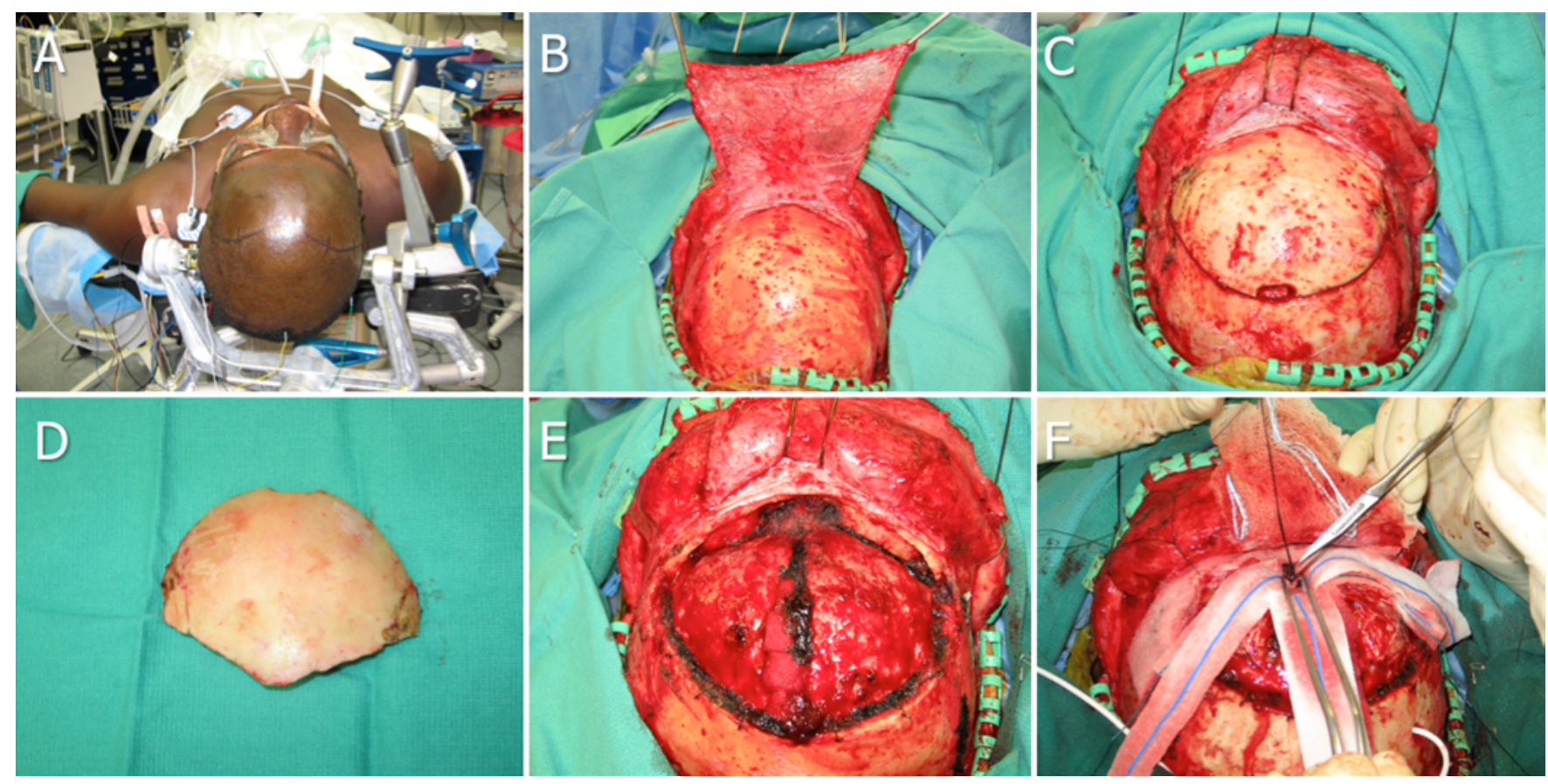

FIG. 1. Photographs showing the modified 1-piece extended transbasal approach. A: The patient is positioned supine, and a bicoronal incision is made. B: A vascularized pedicled pericranial flap is elevated at the time of scalp dissection for later use during the reconstruction. $\mathbf{C}$ and $\mathbf{D}$ : The bifrontal bone flap incorporates the anterior table of the frontal sinus so that the inferior osteotomy starts at the level of the nasofrontal suture and follows the contour of the anterior fossa floor in the coronal plane. $\mathrm{E}$ : This allows a very basal exposure so that there is no bony overhang to obstruct the line of sight to the cribriform plate. The osteotomy is at the level of the orbital roofs laterally so that additional supraorbital bar removal is unnecessary. F: A low subfrontal dural incision is made bilaterally, and the sagittal sinus is ligated with sutures and then sharply divided. The incision is continued along the falx cerebri to the free edge to provide interhemispheric access to the OGM. 

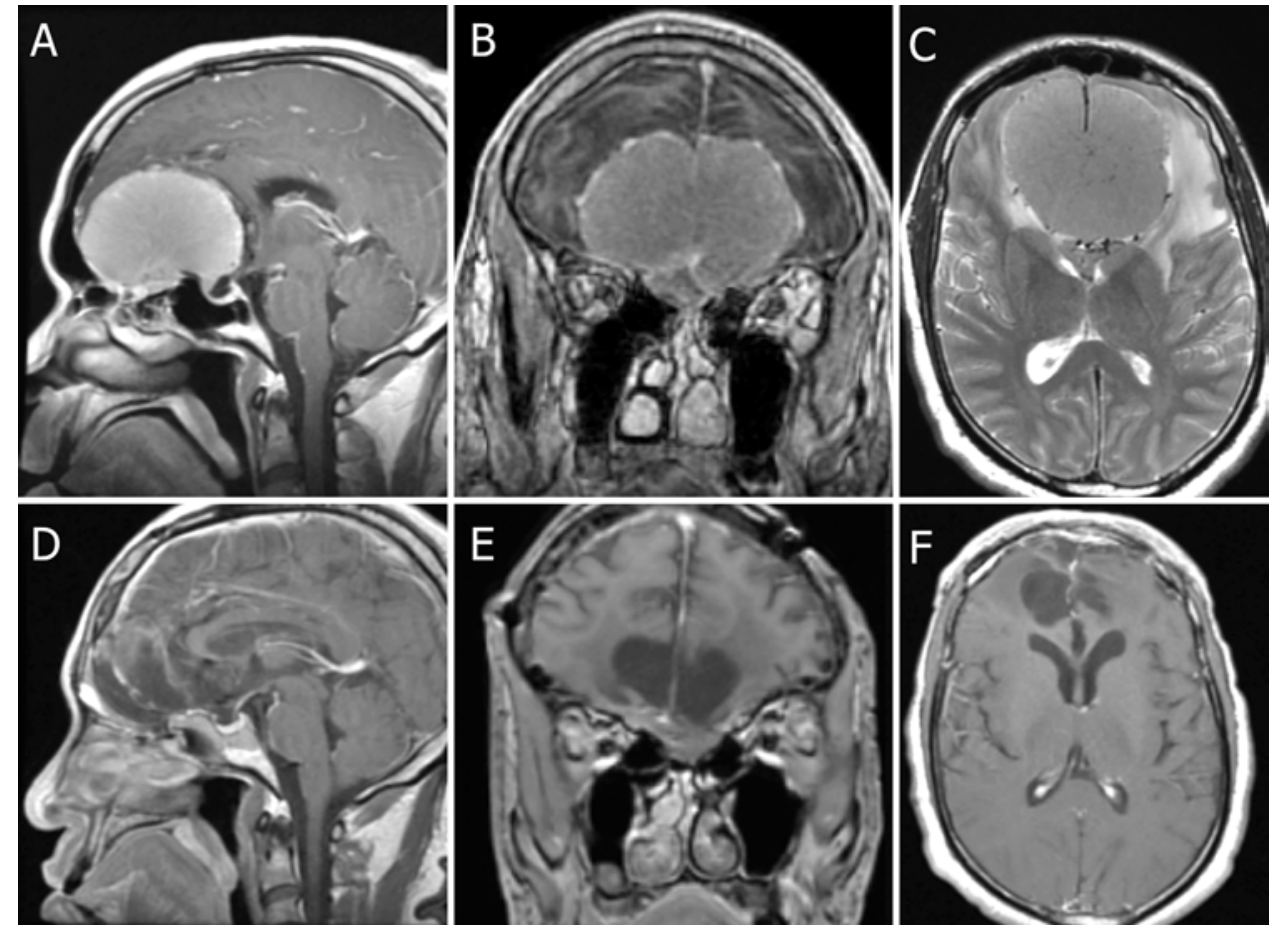

FIG. 2. A-C: Preoperative sagittal (A) and coronal (B) post-Gd T1-weighted and axial T2-weighted (C) MR images demonstrating a large, $53.3 \times 69.7 \times 69.2-\mathrm{mm}$ OGM with significant lateral extension over the orbits and anterior extension to the posterior table of the frontal sinus. There was also vascular involvement without a cortical cuff and associated cerebral edema (C, lion's mane sign). GTR (Simpson grade I) was achieved via the transbasal approach. D-F: Postoperative post-Gd T1-weighted sagittal (D), coronal $(E)$, and axial $(F)$ MR images showing complete removal without any residual or recurrent tumor.
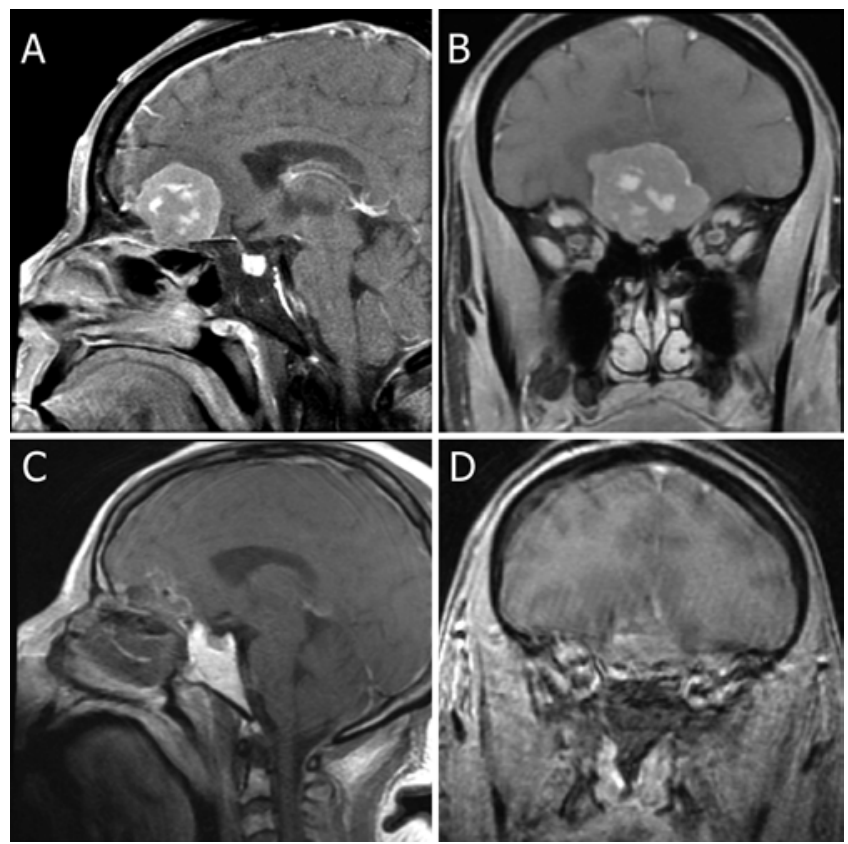

FIG. 3. A and B: Preoperative sagittal (A) and coronal (B) post-Gd T1-weighted MR images demonstrating a $32.5 \times 36.0 \times 35.8-\mathrm{mm}$ OGM without lateral dural extension. Because of the presence of a cortical cuff and absence of functional olfaction, an EEA was performed to achieve GTR (Simpson grade I). C and D: Postoperative sagittal (C) and coronal (D) post-Gd T1-weighted MR images did not show any enhancing residual tumor.

\section{Extent of Resection}

GTR and NTR were achieved in all 28 cases (Table 2). GTR was achieved in $80 \%$ of transbasal, $100 \%$ of EEA, and $62.5 \%$ of combined cases $(\mathrm{p}=0.271)$. NTR was achieved in $20 \%$ of transbasal and $37.5 \%$ of combined cases. The primary factors resulting in NTR were operating on a recurrent tumor $(83.3 \%, \mathrm{p}<0.004)$ and tumor adherence to the optic nerve (100\%) and/or important vasculature $(66.7 \%$, $\mathrm{p}=0.025$ ). If recurrent tumors were eliminated from the analysis of both the transbasal and EEA groups, GTR was achieved in $92.3 \%$ (12 of 13) of the transbasal and $100 \%$ (4 of 4) of the EEA groups. All tumors in the combined group were recurrent OGMs with sinonasal invasion that had previously been treated via craniotomy, and had the highest rate of optic nerve adherence $(62.5 \%, \mathrm{p}=0.011)$. In our study, there was only 1 recurrence after EEA for a GTR of a recurrent OGM in the sinonasal cavity. This new recurrence occurred in the left orbit, resulting in proptosis. The patient underwent another EEA for medial orbital decompression and subtotal debulking, followed by radiation therapy. The proptosis improved and there has not been any further tumor progression.

\section{Postoperative Olfaction}

Olfaction was preserved in none of the EEA and combined cases, as the transcribriform approach inevitably destroys the olfactory nerves when transgressing the cribriform plate. Of the 6 patients who had intact and salvageable preoperative olfaction in the transbasal group, 4 pa- 

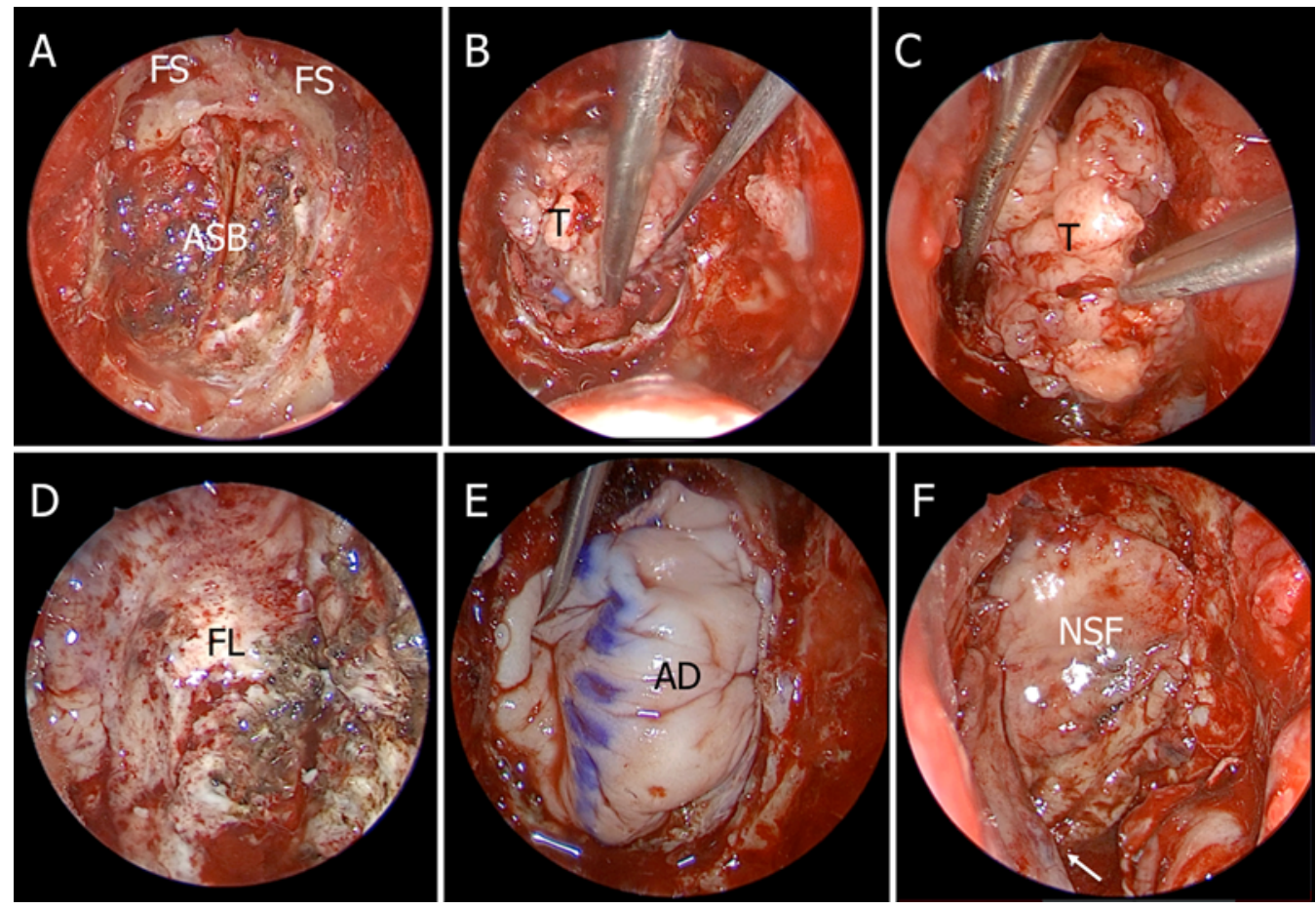

FIG. 4. Intraoperative photographs obtained with a $30^{\circ}$-angled endoscope with upward viewing of the ventral skull base of the patient in Fig. 3. A: View of the ventral keyhole anterior skull base (ASB) craniectomy that extends from the posterior table of the frontal sinus (FS) toward the planum sphenoidale in the sagittal plane, and from the lamina papyracea to the lamina papyracea in the coronal plane. The ASB dura is coagulated to devascularize the tumor. B and C: The dura is opened, and after internal tumor debulking, the tumor $(T)$ is carefully dissected away from the frontal lobes in an extracapsular fashion. D: View of the frontal lobe $(\mathrm{FL})$ resection cavity after tumor removal. E: Two pieces of AlloDerm (AD; LifeCell Corp.) are tucked underneath the skull base defect. F: A vascularized pedicled nasoseptal flap (NSF) is rotated into position to provide coverage over the skull base defect. A relaxing sphenoidal slit incision (arrow) is made to increase the anterior and posterior reach of the flap so that the flap makes contact with the posterior table of the frontal sinus anteriorly and the planum sphenoidale posteriorly. The vascular pedicle remains intact.

tients $(66.7 \%)$ had preservation of olfaction. The remaining patients lost smell due to tumor infiltration and tumor removal.

\section{Complications}

In the overall series, there were no incidences of optic nerve or vascular injuries. The overall CSF leakage rate was $3.6 \%$, which occurred in 1 patient in the EEA group $(20 \%)$. No patient in the transbasal or combined transbasal-EEA group had postoperative CSF leakage (0\%). There were no complications in the transbasal group. However, in the combined group, there was 1 patient $(12.5 \%)$ who had postoperative pneumocephalus and bone flap infection, and 1 patient $(12.5 \%)$ who had frontal sinusitis. In the EEA group, 1 patient (20\%) had a postoperative hematoma requiring endonasal evacuation followed by a delayed abscess that was treated with antibiotics, and another patient $(20 \%)$ had a postoperative CSF leak that resulted in meningitis. There were no 30-day mortalities.

\section{LOS and 30-Day Readmission}

There were no significant differences in hospital LOS between the 3 groups (mean 6.6 days for transbasal cases, 4.2 days for EEA cases, and 5.3 days for combined transbasal-EEA cases; $\mathrm{p}=0.309$ ). There was no significant difference in 30-day readmission between the 3 groups
(13.3\% of transbasal cases, $20 \%$ of EEA cases, and $25 \%$ of combined approach cases). Follow-up was a mean of 14.5 months (range 1-76 months). Overall, the transbasal group had the lowest rate of complications and the best surgical outcomes (mean mRS score 0.79 ; Table 2).

\section{Discussion}

Approach selection is critical for successful outcomes when managing OGMs. Tumor size, involvement of neurovascular structures and the optic nerves, presence of olfaction, invasion of the cribriform plate and sinonasal cavity, and lateral dural extension are characteristics that factor into the optimal approach selection. ${ }^{4,21,30}$ We used all 3 approaches for specific tumor characteristics and achieved comparable results in all 3 groups. There were no significant differences in LOS and 30-day readmission rates between the 3 groups. As such, the results of our current study reflect careful approach selection for each patient based on tumor and patient characteristics. Overall, the transbasal group had the lowest rate of complications and the best surgical outcomes (mean mRS score 0.79; Table 2).

\section{Role of the Transbasal Approach}

In our current study, the transbasal approach, with and without endoscope assistance, was the main workhorse 

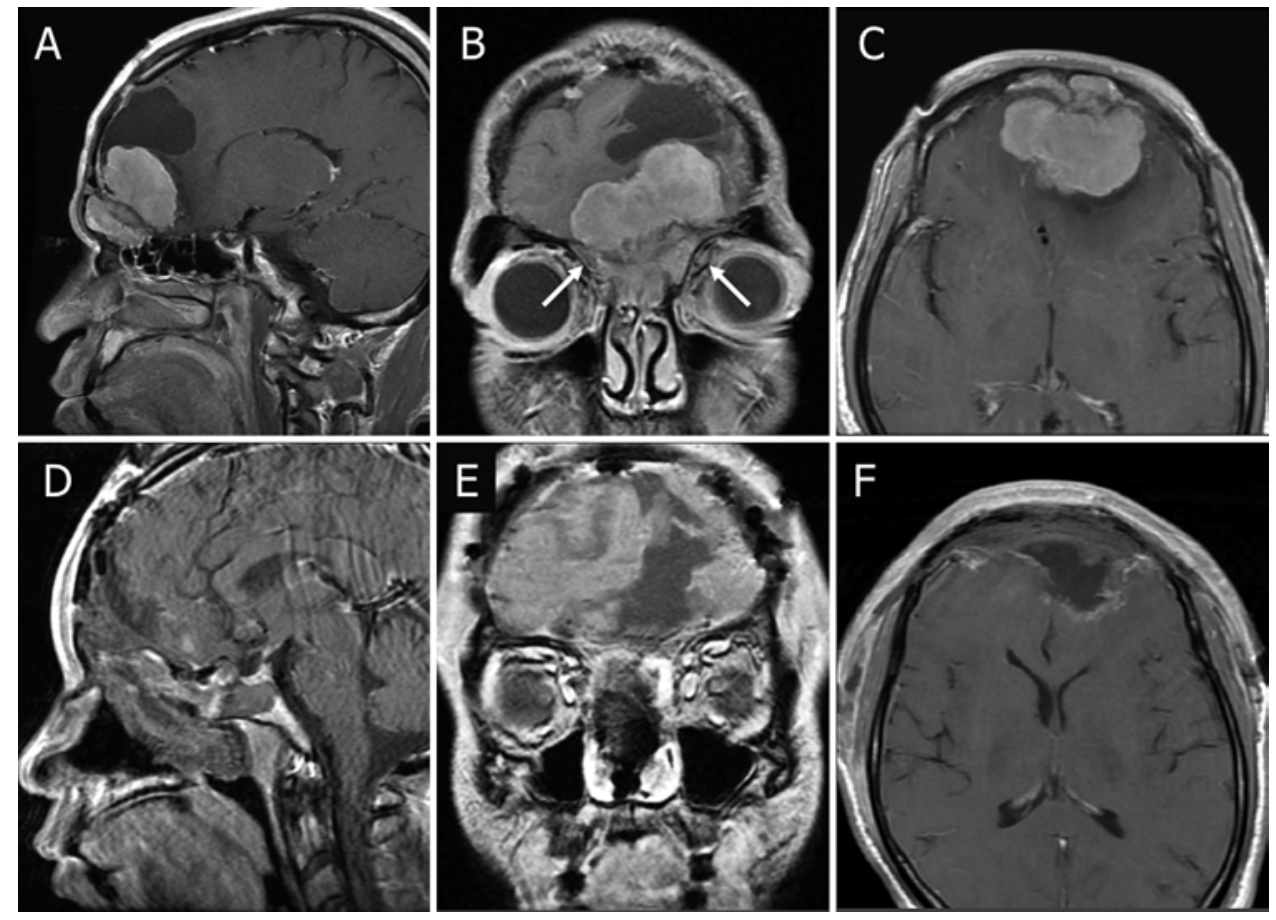

FIG. 5. A-C: Preoperative sagittal (A), coronal (B), and axial (C) post-Gd T1-weighted MR images demonstrating a recurrent OGM extending laterally across both orbital roofs (arrows) with extension into the frontal sinus through the posterior table. GTR (Simpson grade I) was achieved via a combined transbasal-EEA. D-F: Postoperative sagittal (D), coronal (E), and axial (F) post-Gd T1-weighted MR images showing complete removal without any residual tumor.

and was used in $82.1 \%$ (23 of 28 ) of cases. We favor the transbasal interhemispheric corridor over unilateral anterolateral approaches because it provides wide midline visualization of the anterior skull base with the ability to resect tumor that extends laterally over both orbits and optic canals, and inferiorly into the sinonasal cavity (Fig. 1). A large vascularized pericranial flap can be harvested for reconstruction of the skull base defect to prevent CSF leakage. In addition, there is earlier control of the anterior cerebral arteries and anterior communicating artery complex using the interhemispheric corridor, which can minimize the potential for vascular injury. Moreover, in the event of a vascular injury, it is more feasible to apply temporary clips for direct vessel repair or anastomosis in an open approach than in a narrow endonasal corridor. There was also very minimal use of fixed retraction since the larger tumors $(>40 \mathrm{~mm})$ provided a natural working corridor via the interhemispheric fissure, thereby avoiding any subfrontal retraction. Although an eyebrow incision or supraorbital approach is used by some surgeons for OGMs, ${ }^{1,12,36}$ we feel that the viewing angle to the cribriform region is oblique and can be obscured by a "steep" orbital roof, even with extensive bone drilling to flatten this trajectory. Although the use of an angled endoscope can enhance the view of the "valley" of the cribriform plate between the 2 orbits, having control of both olfactory nerves and a direct view into the sinonasal cavity can be difficult. We therefore favor the transbasal approach, which provides a wide midline exposure with a direct view of both olfactory nerves (for olfaction preservation) and a direct view into the sinonasal cavity, if needed.
In this study, the transbasal approach had the best clinical outcomes (mean mRS score 0.79) with the lowest rate of complications and CSF leakage (0\%). A wide range of tumor sizes, ranging from 16.9 to $91.4 \mathrm{~mm}$ (mean 44.54 $\mathrm{mm}$ ), were treated in this group (Fig. 2). For the larger tumors in this group, the transbasal approach was chosen because of tumor size $(>40 \mathrm{~mm})$, extent of tumor (lateral extension over the orbits and optic canals and anterior extension to the posterior table of the frontal sinus), vascular involvement, cerebral edema (including the presence of a lion's mane sign), ${ }^{24}$ and absence of a cortical cuff. Smaller tumors $(<40 \mathrm{~mm})$ in this group were also chosen for the transbasal approach because of preoperative intact olfaction, lateral tumor extension, and vascular involvement. GTR was achieved in $80 \%$, while the remaining 3 patients underwent NTR due to tumor adherence to neurovascular structures. There were no CSF leaks ( $0 \%)$, no vascular injuries $(0 \%)$, and no recurrences. We think that the transbasal approach is a safe and effective procedure that can be performed with low risks of morbidity.

\section{Role of EEA for OGMs}

The role of EEA for OGMs continues to be an area of controversy. Recent studies have shown the limitations of EEA for OGMs when compared with transcranial techniques. A recent systematic review by Shetty et al. ${ }^{37} \mathrm{dem}-$ onstrated that EEA had a lower rate of GTR (70.2\%), a higher rate of loss of olfaction (100\%), and a higher rate of CSF leak (25.7\%) than the transcranial group $(90.9 \%, 61 \%$, and $6.3 \%$, respectively). Koutourousiou et al. ${ }^{22}$ reported 

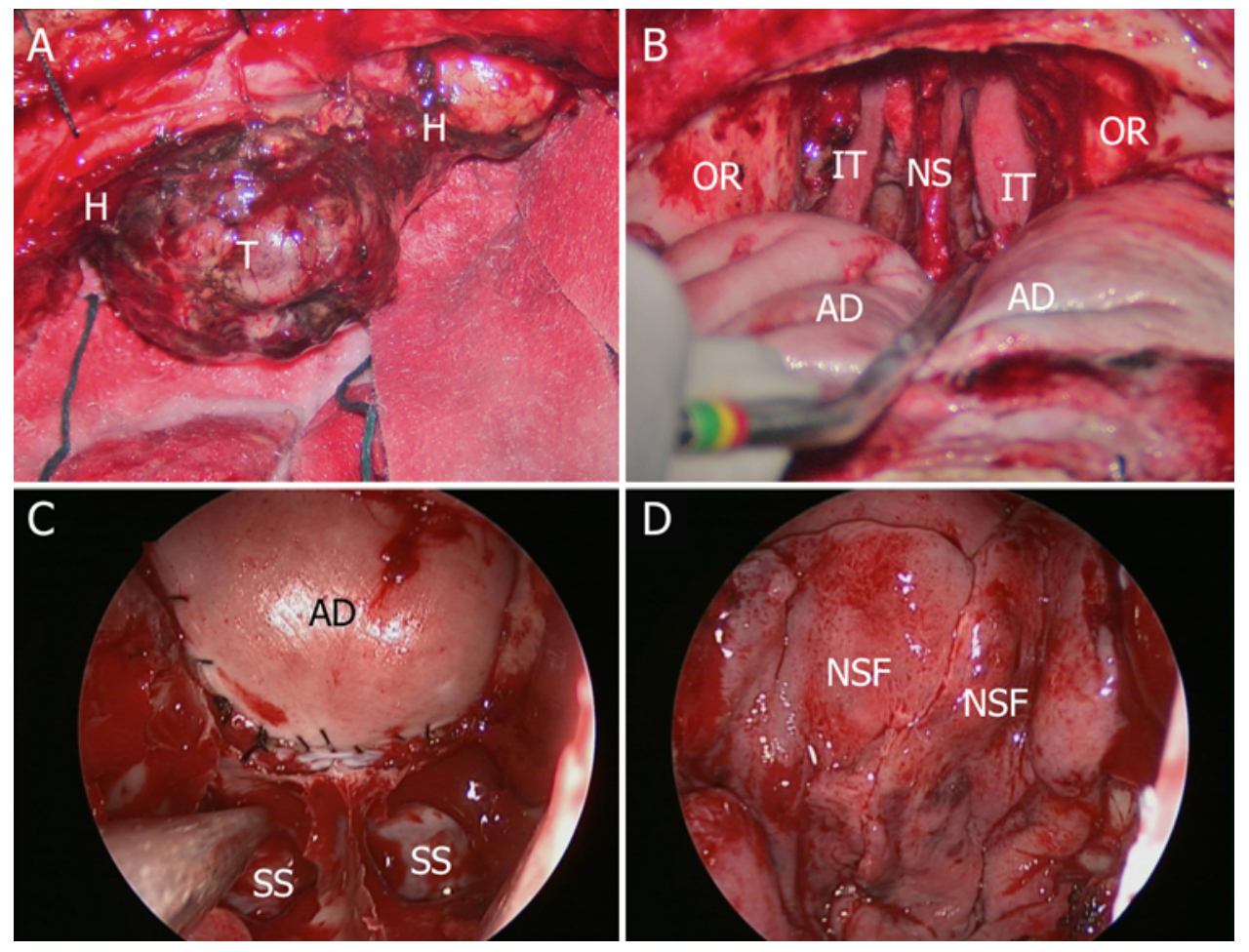

FIG. 6. Intraoperative microsurgical photographs from the transbasal view. A: The tumor $(T)$ is visualized at the anterior skull base extending laterally over both orbits. There is significant hyperostosis $(\mathrm{H})$ of the inner table of the frontal bone. The intracranial and extracranial portions of the tumor are removed from the transbasal corridor, and the hyperostosic bone is completely drilled off. B: After tumor removal, the dura is repaired primarily with an AlloDerm (AD) patch graft and the nasal septum (NS) and inferior turbinates (IT) are visualized between the 2 orbital roofs (OR). C: Endoscopic endonasal inspection shows no evidence of residual tumor in the nasal cavity, and the AlloDerm patch graft is shown in the skull base defect. D: Because there is no available pericranial flap from prior usage, the defect is repaired endoscopically with a nasoseptal flap (NSF). In this specific case, bilateral nasoseptal flaps were used.

one of the largest series of 50 patients who underwent EEA for OGMs. The majority of the tumors treated $(56 \%)$ were larger than $40 \mathrm{~mm}$. GTR was achieved in $66.7 \%$, with residual tumor at the most lateral and anterior margins. Significant lateral and anterior dural involvement, calcification, and absence of a cortical cuff limited the ability of GTR with the EEA. The postoperative CSF leakage rate was $30 \%$. It was noted by the authors that tumors larger than $40 \mathrm{~mm}$ were associated with increased complications with EEA, which suggests that these tumors might be better treated with transcranial approaches. Banu et al. ${ }^{1}$ also reported a complication rate of $83.3 \%$ for patients underdoing an EEA for OGMs, which has resulted in these authors favoring a transcranial approach. Therefore, some have suggested that EEA may be more ideal for smaller tumors between 30 and $40 \mathrm{~mm} \cdot{ }^{36}$ However, patients with smaller tumors tend to have intact olfaction, and an EEA would result in more morbidity because of postoperative anosmia. Therefore, a transcranial approach that can attempt to preserve olfaction should be favored, even for the smaller tumors that can be considered "safer" for EEA.

In our series, we cautiously reserved EEA for carefully selected patients who had preoperative impaired olfaction and whose tumors did not have any anterior or lateral tumor extension but had a cortical cuff (Figs. 3 and 4). Although GTR was $100 \%$, one patient with a larger tumor
$(44.2 \mathrm{~mm})$ had a postoperative hematoma that required endonasal evacuation, and a delayed postoperative abscess developed. Another patient had a postoperative CSF leak associated with meningitis. In our series, the transbasal and combined transbasal-EEA groups still had a lower rate of CSF leakage (0\%) and a lower rate of complications

TABLE 2. Clinical outcomes after resection of OGMs

\begin{tabular}{lcccc}
\hline \multicolumn{1}{c}{ Variable } & $\begin{array}{c}\text { Transbasal } \\
(n=15)\end{array}$ & $\begin{array}{c}\text { EEA } \\
(\mathrm{n}=5)\end{array}$ & $\begin{array}{c}\text { Combined } \\
(\mathrm{n}=8)\end{array}$ & $\begin{array}{c}\mathrm{p} \\
\text { Value }\end{array}$ \\
\hline GTR & $12(80.0)$ & $5(100.0)$ & $5(62.5)$ & 0.271 \\
\hline \multicolumn{1}{c}{ Simpson grade I } & $8(53.3)$ & $5(100.0)$ & $4(50.0)$ & \\
\hline \multicolumn{1}{c}{ Simpson grade II } & $2(13.3)$ & $0(0)$ & $1(12.5)$ & \\
\hline NTR & $3(20.0)$ & $0(0)$ & $3(37.5)$ & \\
\hline CSF leak & $0(0)$ & $1(20.0)$ & $0(0)$ & \\
\hline $\begin{array}{l}\text { Mean LOS in days } \\
\pm \text { SD }\end{array}$ & $6.6 \pm 3.52$ & $4 \pm 3.11$ & $5.25 \pm 2.38$ & 0.309 \\
\hline 30-day readmission & $2(13.3)$ & $1(20.0)$ & $2(25.0)$ & \\
\hline Complications & $0(0)$ & $2(40.0)$ & $2(25.0)$ & \\
\hline Mean mRS score & 0.79 & 2.0 & 2.4 & 0.0604 \\
\hline Olfaction preservation & 4 of $6(66.7)$ & $0(0)$ & $0(0)$ & \\
\hline
\end{tabular}

Values are presented as the number of patients (\%) unless stated otherwise. 
$(8.7 \%)$. We think that the presence of a cortical cuff can affect overall outcome when considering the EEA, specifically for OGMs. The cortical cuff provides a protective layer of noneloquent brain tissue from the anterior cerebral vessels, thereby lessening the risk of a vascular injury. As shown by Koutourousiou et al., ${ }^{22}$ the absence of a cortical cuff can negatively impact the extent of resection.

\section{Role of the Combined Endoscope-Assisted Transbasal Approach}

Our third group of patients had recurrent OGMs that all presented with sinonasal recurrence (Figs. 5 and 6). These patients all had prior craniotomies during which the pericranial flap had already been used (in 87.5\%). In addition to sinonasal recurrence, $100 \%$ had lateral dural extension, $12.5 \%$ had intraorbital invasion, $62.5 \%$ had optic nerve involvement, and $37.5 \%$ had vascular involvement. This group underwent a combined approach during which tumor resection was performed primarily from the transbasal corridor, and the EEA served as an adjunct for endonasal inspection and nasoseptal flap reconstruction. Although the combined group had the lowest GTR rate of $62.5 \%$ (due to tumor adhesions to neurovascular structures in recurrent tumors), there were no vascular injuries and no postoperative CSF leaks. Complications in this group included one patient with frontal sinusitis and another with pneumocephalus and a bone flap infection. Banu et al. ${ }^{1}$ also reported 6 cases of OGMs that were treated with a combined approach (bicoronal or eyebrow supraorbital combined with EEA) to address sinonasal tumor extension that had similar results to our series. GTR was achieved in $66.7 \%$ without any CSF leaks. One patient had complications of visual field deficit, and another patient had a postoperative infection requiring a wound washout.

\section{Olfaction Preservation}

OGMs grow slowly over time before becoming large enough to unilaterally or bilaterally compress the olfactory nerves and subsequently cause anosmia, phantosmia, dys-

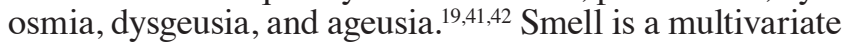
component of a patient's quality of life, as it impacts social and cultural experiences. ${ }^{19,42}$ Youssef et al.$^{42}$ described smell as an important part of the limbic system, in which anosmia can cause psychological impairments. Thus, the functional outcome of smell should be a pertinent consideration for the patient when the surgical approach is chosen. ${ }^{19,30,42}$ The endoscopic endonasal transcribriform approach to OGMs invariably sacrifices olfaction by nature of resection of the cribriform plate and division of the olfactory tracts. The one rare exception where olfaction can be preserved is a unilateral endoscopic transcribriform approach for small unilateral OGM originating from one cribriform plate without extension to the contralateral cribriform plate. ${ }^{42}$

In our current series, no patient who underwent an EEA or combined transbasal-EEA had any olfaction preoperatively or postoperatively. However, in the transbasal group, of the 6 patients who had intact smell preoperatively, olfaction was preserved in $66.7 \%$ (4 patients), which is higher than that reported in the literature $(38.1 \%) .{ }^{37}$ This was achieved in small to medium tumors $(<40 \mathrm{~mm})$ by carefully preserving both olfactory bulbs and tracts. All other tumors in the transbasal group were larger than 40 $\mathrm{mm}$ without any preoperative olfaction. Although smaller tumors can be enticing for EEA, patients who have intact smell should be considered for a transcranial approach in order to attempt olfaction preservation. The midline orientation of the transbasal approach also allows direct vision and control of both olfactory nerves. Only those tumors with impaired olfaction should be considered for EEA.

\section{Complication Avoidance}

In our current study, the CSF leakage rate in the transbasal and combined groups was $0 \%$, and there was only 1 leak in the EEA group (20\%). These results are comparable to those of a recent systematic review in which the overall CSF leakage rate was $6.3 \%$ after transcranial approaches and $25.7 \%$ after EEA. ${ }^{37}$ These data suggest that there is still a significant rate of CSF leakage after EEA for OGMs, even with improved reconstruction techniques with the nasoseptal flap. In the study by Koutourousiou et al., tumors larger than $40 \mathrm{~mm}$ were associated with a higher rate of CSF leakage than tumors smaller than $40 \mathrm{~mm}(39.3 \%$ vs $18.2 \%) .{ }^{22}$ This is probably due to bilateral superomedial orbitectomies that were performed to access lateral extension over the orbits in larger and giant OGMs, resulting in a larger skull base defect that is more challenging to repair successfully. We believe that our success in preventing CSF leakage is largely due to a multilayered, watertight closure from above before supplementing the repair with a pericranial flap (transbasal group) or nasoseptal flap (combined group). We prefer not to perform superomedial orbitectomies during EEA so that there is a bony shelf to tuck inlay graft material ${ }^{10}$ and also to limit the skull base defect size to reduce complications of CSF leakage.

In a recent cost minimization analysis by Gandhoke et al., ${ }^{12}$ EEA was found to be associated with a longer LOS than that for supraorbital transcranial approaches (11 vs 2.3 days). Their study demonstrated longer hospital and ICU LOSs as a result of CSF leakage complications after EEA. Ultimately, supraorbital craniotomy provided a substantial cost savings (ranging from $\$ 46,000$ to $\$ 64,000$ ) from the hospital perspective compared with EEA for treatment of OGM. This difference can be attributed to the increased costs of EEA; utilizing 2 surgical teams (neurosurgery and otolaryngology); sometimes staging the procedure, which can result in added costs and operating time; and the increased LOS and ICU stays from CSF leakage complications. ${ }^{12}$

\section{Conclusions}

Careful patient selection for each approach using a personalized, tailored strategy is important to optimize surgical outcomes and avoid complications. In our practice, the transbasal approach remains the workhorse for removing larger, complex tumors with wide lateral extension over the orbits, as well as for smaller tumors that have intact olfaction. The role of pure EEA remains limited to smaller, appropriately selected OGMs without intact olfaction, lateral dural extension, and vascular involvement. EEA also plays an important adjunctive role in sinonasal inspection 
and nasoseptal flap reconstruction when combined with a transbasal approach for recurrent OGMs that invade the paranasal sinuses.

\section{References}

1. Banu MA, Mehta A, Ottenhausen M, Fraser JF, Patel KS, Szentirmai O, et al: Endoscope-assisted endonasal versus supraorbital keyhole resection of olfactory groove meningiomas: comparison and combination of 2 minimally invasive approaches. J Neurosurg 124:605-620, 2016

2. Barzaghi LR, Spina A, Gagliardi F, Boari N, Mortini P: Transfrontal-sinus-subcranial approach to olfactory groove meningiomas: surgical results and clinical and functional outcome in a consecutive series of 21 patients. World Neurosurg 101:315-324, 2017

3. Bassiouni H, Asgari S, Stolke D: Olfactory groove meningiomas: functional outcome in a series treated microsurgically. Acta Neurochir (Wien) 149:109-121, 2007

4. Bitter AD, Stavrinou LC, Ntoulias G, Petridis AK, Dukagjin M, Scholz M, et al: The role of the pterional approach in the surgical treatment of olfactory groove meningiomas: a 20year experience. J Neurol Surg B Skull Base 74:97-102, 2013

5. Bloch RF: Interobserver agreement for the assessment of handicap in stroke patients. Stroke 19:1448, 1988

6. de Almeida JR, Carvalho F, Vaz Guimaraes Filho F, Kiehl TR, Koutourousiou M, Su S, et al: Comparison of endoscopic endonasal and bifrontal craniotomy approaches for olfactory groove meningiomas: a matched pair analysis of outcomes and frontal lobe changes on MRI. J Clin Neurosci 22:17331741,2015

7. DeMonte F: Surgical treatment of anterior basal meningiomas. J Neurooncol 29:239-248, 1996

8. Downes AE, Freeman JL, Ormond DR, Lillehei KO, Youssef AS: Unilateral tailored fronto-orbital approach for giant olfactory groove meningiomas: technical nuances. World Neurosurg 84:1166-1173, 2015

9. Eloy JA, Marchiano E, Vázquez A, Pfisterer MJ, Mady LJ, Baredes S, et al: Management of skull base defects after surgical resection of sinonasal and ventral skull base malignancies. Otolaryngol Clin North Am 50:397-417, 2017

10. Eloy JA, Patel SK, Shukla PA, Smith ML, Choudhry OJ, Liu JK: Triple-layer reconstruction technique for large cribriform defects after endoscopic endonasal resection of anterior skull base tumors. Int Forum Allergy Rhinol 3:204-211, 2013

11. Fernandez-Miranda JC, Gardner PA, Prevedello DM, Kassam AB: Expanded endonasal approach for olfactory groove meningioma. Acta Neurochir (Wien) 151:287-290, 2009

12. Gandhoke GS, Pease M, Smith KJ, Sekula RF Jr: Supraorbital versus endoscopic endonasal approaches for olfactory groove meningiomas: a cost-minimization study. World Neurosurg 105:126-136, 2017

13. Gardner PA, Kassam AB, Thomas A, Snyderman CH, Carrau RL, Mintz AH, et al: Endoscopic endonasal resection of anterior cranial base meningiomas. Neurosurgery 63:36-54, 2008

14. Gazzeri R, Galarza M, Gazzeri G: Giant olfactory groove meningioma: ophthalmological and cognitive outcome after bifrontal microsurgical approach. Acta Neurochir (Wien) 150:1117-1126, 2008

15. Guduk M, Yener U, Sun HI, Hacihanefioglu M, Ozduman K, Pamir MN: Pterional and unifrontal approaches for the microsurgical resection of olfactory groove meningiomas: experience with 61 consecutive patients. Turk Neurosurg 27:7007-715, 2017

16. Guinto G: Olfactory groove meningiomaas. World Neurosurg 83:1046-1047, 2015

17. Hasegawa H, Shin M, Kondo K, Hanakita S, Mukasa A, Kin
$\mathrm{T}$, et al: Role of endoscopic transnasal surgery for skull base chondrosarcoma: a retrospective analysis of 19 cases at a single institution. J Neurosurg [epub ahead of print July 7, 2017; DOI: 10.3171/2017.1.JNS162000]

18. Hassler W, Zentner J: Pterional approach for surgical treatment of olfactory groove meningiomas. Neurosurgery 25:942-947, 1989

19. Jang WY, Jung S, Jung TY, Moon KS, Kim IY: Preservation of olfaction in surgery of olfactory groove meningiomas. Clin Neurol Neurosurg 115:1288-1292, 2013

20. Khan OH, Anand VK, Schwartz TH: Endoscopic endonasal resection of skull base meningiomas: the significance of a "cortical cuff" and brain edema compared with careful case selection and surgical experience in predicting morbidity and extent of resection. Neurosurg Focus 37(4):E7, 2014

21. Komotar RJ, Starke RM, Raper DM, Anand VK, Schwartz TH: Endoscopic endonasal versus open transcranial resection of anterior midline skull base meningiomas. World Neurosurg 77:713-724, 2012

22. Koutourousiou M, Fernandez-Miranda JC, Wang EW, Snyderman $\mathrm{CH}$, Gardner PA: Endoscopic endonasal surgery for olfactory groove meningiomas: outcomes and limitations in 50 patients. Neurosurg Focus 37(4):E8, 2014

23. Kunicki A, Uhl A: The clinical picture and results of treatment in 26 cases of olfactory groove meningiomas. Acta Med Pol 11:103-117, 1970

24. Li MS, Portman SM, Rahal A, Mohr G, Balasingam V: The lion's mane sign: surgical results using the bilateral frontoorbito-nasal approach in large and giant anterior skull base meningiomas. J Neurosurg 120:315-320, 2014

25. Liu JK: Modified one-piece extended transbasal approach for translamina terminalis resection of retrochiasmatic third ventricular craniopharyngioma. Neurosurg Focus 34 (1 Suppl):Video 1, 2013

26. Liu JK, Christiano LD, Gupta G, Carmel PW: Surgical nuances for removal of retrochiasmatic craniopharyngiomas via the transbasal subfrontal translamina terminalis approach. Neurosurg Focus 28(4):E6, 2010

27. Liu JK, Christiano LD, Patel SK, Tubbs RS, Eloy JA: Surgical nuances for removal of olfactory groove meningiomas using the endoscopic endonasal transcribriform approach. Neurosurg Focus 30(5):E3, 2011

28. Liu JK, Decker D, Schaefer SD, Moscatello AL, Orlandi RR, Weiss $\mathrm{MH}$, et al: Zones of approach for craniofacial resection: minimizing facial incisions for resection of anterior cranial base and paranasal sinus tumors. Neurosurgery 53:1126-1137, 2003

29. Liu JK, Eloy JA: Modified one-piece extended transbasal approach for resection of giant anterior skull base sinonasal teratocarcinosarcoma. J Neurosurg 32 Suppl:E4, 2012

30. Liu JK, Hattar E, Eloy JA: Endoscopic endonasal approach for olfactory groove meningiomas: operative technique and nuances. Neurosurg Clin N Am 26:377-388, 2015

31. Liu JK, Schmidt RF, Choudhry OJ, Shukla PA, Eloy JA: Surgical nuances for nasoseptal flap reconstruction of cranial base defects with high-flow cerebrospinal fluid leaks after endoscopic skull base surgery. Neurosurg Focus 32(6):E7, 2012

32. Liu JK, Wong A, Eloy JA: Combined endoscopic and open approaches in the management of sinonasal and ventral skull base malignancies. Otolaryngol Clin North Am 50:331346, 2017

33. Nakamura M, Struck M, Roser F, Vorkapic P, Samii M: Olfactory groove meningiomas: clinical outcome and recurrence rates after tumor removal through the frontolateral and bifrontal approach. Neurosurgery 60:844-852, 2007

34. Pallini R, Fernandez E, Lauretti L, Doglietto F, D'Alessandris QG, Montano N, et al: Olfactory groove meningioma: report of 99 cases surgically treated at the Catho- 
lic University School of Medicine, Rome. World Neurosurg 83:219-231,231.e1-231.e3, 2015

35. Prevedello DM, Ditzel Filho LF, Fernandez-Miranda JC, Solari D, do Espírito Santo MP, Wehr AM, et al: Magnetic resonance imaging fluid-attenuated inversion recovery sequence signal reduction after endoscopic endonasal transcribiform total resection of olfactory groove meningiomas. Surg Neurol Int 6:158, 2015

36. Schwartz TH: Should endoscopic endonasal surgery be used in the treatment of olfactory groove meningiomas? Neurosurg Focus 37(4):E9, 2014

37. Shetty SR, Ruiz-Trevino AS, Omay SB, Almeida JP, Liang B, Chen YN, et al: Limitations of the endonasal endoscopic approach in treating olfactory groove meningiomas. A systematic review. Acta Neurochir (Wien) 159:1875-1885, 2017

38. Simpson D: The recurrence of intracranial meningiomas after surgical treatment. J Neurol Neurosurg Psychiatry 20:22-39, 1957

39. Spektor S, Valarezo J, Fliss DM, Gil Z, Cohen J, Goldman J, et al: Olfactory groove meningiomas from neurosurgical and ear, nose, and throat perspectives: approaches, techniques, and outcomes. Neurosurgery 57 (4 Suppl):268-280, 2005

40. Tomasello F, Angileri FF, Grasso G, Granata F, De Ponte FS, Alafaci C: Giant olfactory groove meningiomas: extent of frontal lobes damage and long-term outcome after the pterional approach. World Neurosurg 76:311-317, 255-258, 2011

41. Venteicher AS, Kumar JI, Murphy EA, Gray ST, Holbrook EH, Curry WT: Phantosmia and dysgeusia following endo- scopic transcribriform approaches to olfactory groove meningiomas. J Neurol Surg B Skull Base 78:245-250, 2017

42. Youssef AS, Sampath R, Freeman JL, Mattingly JK, Ramakrishnan VR: Unilateral endonasal transcribriform approach with septal transposition for olfactory groove meningioma: can olfaction be preserved? Acta Neurochir (Wien) 158:1965-1972, 2016

\section{Disclosures}

The authors report no conflict of interest concerning the materials or methods used in this study or the findings specified in this paper.

\section{Author Contributions}

Conception and design: Liu, Sevak. Acquisition of data: Liu, Sevak, Eloy. Analysis and interpretation of data: Liu, Silva, Sevak. Drafting the article: all authors. Critically revising the article: all authors. Reviewed submitted version of manuscript: all authors. Approved the final version of the manuscript on behalf of all authors: Liu. Statistical analysis: Silva. Administrative/technical/ material support: Liu, Eloy. Study supervision: Liu, Eloy.

\section{Correspondence}

James K. Liu: Rutgers Neurological Institute of New Jersey, Rutgers University-New Jersey Medical School, Newark, NJ. james. liu.md@rutgers.edu. 